\title{
O Pó Revelador e o seu Processo de Adesão aos Resquícios Presentes nas Impressóes Papilares latentes
}

\author{
Daniel da Silva Carvalho \\ Polícia Federal - Brasília/DF \\ WILIAM FERREIRA DA CUNHA \\ Universidade de Brasília (UnB) \\ BERNARDO JOSÉ MUNHOZ LOBO \\ Polícia Federal - Brasília/DF
}

PEDRO HENRIQUE DE OLIVEIRA NETO

Universidade De Brasília (UnB)

$\approx$

\section{RESUMO}

Por meio de uma revisão da literatura especializada, o presente estudo se propõe a divulgar e detalhar os aspectos técnico-científicos relacionados a alguns dos fatores que influenciam o processo de adesão do pó revelador aos resquícios presentes nas impressóes papilares latentes. Também serão apresentados alguns dos tipos de pós mais comumente utilizados. A distância, a pureza e a natureza química dos componentes da interface pó-crista papilar impressa determinarão se a revelação será efetiva ou não. Nesse sentido, ficará evidente que o balanço energético entre as forças adesivas e coesivas na interface pó-crista papilar impressa está relacionado às interações intermoleculares, ao tamanho, à forma, à energia livre de superfície e à molhabilidade entre os componentes dessa interface.

Palavras-chave: Adesão. Pó revelador. Processo físico. Impressão papilar latente. Superfícies porosas. Identificação humana. Direitos humanos.

\section{INTRODUÇÃo}

A aplicação de pó é um método utilizado desde o final do século 19 (FAULDS, 1912) e ainda bastante empregado na revelação e realce de marcas provenientes das palmas das mãos ou das solas dos pés, também dos respectivos dedos, em superfícies não porosas e semiporosas. Apesar de manifestadas na epiderme que recobre essas regiões do 
corpo, a origem desses desenhos se dá nas papilas dérmicas, pequenas saliências de natureza neurovascular localizadas na parte superficial da derme (ASHBAUGH, 1999). Por isso, comumente, tais marcas são denominadas impressões papilares ${ }^{1}$.

Tais desenhos são formados por cristas ou linhas de fricção que se alternam com sulcos (FREITAS et al.,2019). Quando em contato com as mais diversas superfícies, imprimem sobre essas marcas de forma visível ou latente. Se visíveis, são denominadas de impressões papilares visíveis (IPVs); se latentes, de impressões papilares latentes (IPLs).

Tais vestígios possuem características peculiares que permitem a individualização daquele que os produziu e, por isso, se mostram tão importantes no universo investigativo/policial. Inúmeros são os casos em que os exames periciais foram determinantes para a identificação de violações de direitos, não permitindo, desta forma, a perpetuação da impunidade, nem a permanência de casos de pessoas inocentes pagando por crimes que não cometeram (VELHO, 2020).

Comumente mostrada em filmes ou seriados relacionados a investigações policiais, a técnica de pulverizar (ou "empoar") os resquícios das IPLs é bastante consolidada no Brasil. Em outros países não é diferente. Os pós continuam sendo a ferramenta mais utilizada no mundo para este tipo de atividade, por se configurar em um instrumento simples, efetivo, rápido, barato e versátil (BLEAY et al., 2018).

Os pós podem ser utilizados em cenas de crime e em laboratórios, sempre com o objetivo de revelar (deixar visível) as IPLs. Porém, não devem ser aplicados demasiadamente ou sobre superfícies molhadas, sob pena de borrar as IPLs, uma vez que a adesão seletiva aos resquícios presentes nas linhas da IPL pode ficar prejudicada nesses casos. Um bom pó revelador deve possibilitar contraste em relação ao suporte, aderindo muito mais às linhas e liberando os espaços intersticiais (sulcos) de forma a produzir revelações bem definidas.

Existem pós de diferentes cores, formas e composições químicas. Existem, também, diferentes ferramentas para a aplicação dos pós

1 Quando a marca papilar é proveniente dos desenhos dos dedos, recebe o nome de impressão digital. 
reveladores sobre as superfícies, tais como: aplicadores magnéticos, eletrostáticos, borrifadores e os populares pincéis que utilizam pelos de animais ou fibra de vidro. Vale mencionar, inclusive, a existência de aplicadores de pós que evitam a contaminação cruzada de DNA.

O caráter da interface formada entre duas superfícies é dependente da natureza física e química de cada fase/superfície (BERG, 1993). Dessa forma, ao selecionar o pó a ser utilizado em um caso concreto, o especialista deve certificar-se de que os componentes deste não interagirão quimicamente com a superfície sobre a qual as IPLs estão impregnadas e, também, não serão forte e fisicamente atraídos por essa superfície, em detrimento da atração às linhas de fricção impressas sobre esta superfície.

Cabe registrar que as interações físicas (forças intermoleculares) estarão sempre presentes na interface pó/IPLs e que as interações químicas poderão surgir sempre que existir a possibilidade de elétrons serem compartilhados entre moléculas vizinhas ou grupos funcionais, levando a formação de complexos (KEHRWALD, 2009).

De uma maneira geral, não ocorrem reações químicas entre os pós tradicionalmente utilizados e os depósitos presentes nas IPLs, de forma que esse tipo de revelação é caracterizada como física. Os pós aderem mecanicamente aos resíduos úmidos e oleosos das IPLs. A ocorrência de reações químicas neste processo foi algo recentemente agregado à técnica de empoamento, o que se deu por meio da introdução de nanopartículas funcionalizadas aos pós. Este foi o principal avanço no século XXI relacionado à técnica de empoamento (BLEAY et al., 2018).

Apesar de muitos ainda estarem em fase de pesquisa e desenvolvimento, existem pós com nanopartículas que viabilizam ligações químicas com componentes específicos presentes nas IPLs, ou que atuam como aprimoradores de técnicas analíticas que podem ser empregadas posteriormente à revelação das IPLs, de forma a intensificar a detecção de substâncias químicas presentes nestas, tais como explosivos ou drogas proscritas (SOUZA et al.;, 2018); (BARROS, 2019); (CARVALHO, 2019). 
Em contraste, o início do empoamento teve uma abordagem não tão técnica. As prescrições iniciais dos pós e seus métodos de aplicação foram alcançados de maneira puramente empírica, sem um entendimento científico básico do mecanismo de adesão (THOMAS, 1978). Mesmo nos dias de hoje, é possível encontrar especialistas que utilizam a técnica de empoamento, mas possuem pouca familiaridade com os princípios científicos que a justificam.

\section{Objetivos}

Visando sistematizar esses princípios, concentrando-os em um documento técnico único que aborde os aspectos técnicos atinentes ao mecanismo de adesão preferencial dos pós reveladores às linhas presentes nas IPLs, e, também, objetivando promover maior capilarização desses conhecimentos entre os especialistas da área, apresenta-se o presente trabalho.

Cabe ressaltar que, pelo fato de o rigor científico ensejar isenção, o conhecimento e a correta aplicação de princípios científicos aos procedimentos periciais, em última análise, configuram-se ferramentas de promoção de direitos e de manutenção da dignidade da pessoa humana, uma vez que viabilizam a identificação de violações ao ordenamento jurídico pátrio, não permitindo, desta forma, a perpetuação da impunidade.

A identificação de pessoas por meio das impressões digitais (ou a partir de fragmentos destas) desempenha papel de destaque neste contexto, não apenas por potencialmente apresentar suspeitos relacionados ao cometimento de determinado ato delituoso, mas, também, por evitar que sejam imputados crimes a inocentes que não os cometeram.

\section{TEORIA}

Todos os pós empregados na revelação das IPLs utilizam mecanismos de adesão que ocorrem entre as moléculas de um substrato (material que compõe o pó) e as moléculas do outro substrato (material presente nas linhas que formam as IPLs) (BLEAY et al., 2018). Quando 
a força de atração envolve moléculas do mesmo tipo (que pertencem ao mesmo substrato), essa força é denominada de coesão; quando envolve moléculas diferentes, a força passa a ser denominada de adesão (DARVELL, 2018). Em um sentido amplo, a ligação adesiva é simplesmente um processo de fixação de superfície que geralmente é qualificado pela especificação do tipo de atração intermolecular que pode existir entre as superfícies envolvidas (ANUSAVICE et al., 2013).

Para que o processo de adesão seja efetivo, a afinidade do pó com os resquícios presentes nas linhas da impressão a ser revelada deve ser superior à afinidade com a superfície que a alberga (sulcos), proporcionando uma deposição preferencial do pó sobre as linhas de fricção impressas de forma a tingi-las e evidenciar um contraste dessas com os sulcos.

Dito de outra forma, a adesão é a força que faz com que duas diferentes superfícies se liguem quando ocorre um contato íntimo/próximo entre elas (KEHRWALD, 2009). As moléculas de uma se aderem (são atraídas) às moléculas da outra. Uma adesão eficiente vai depender de diversos fatores. Por exemplo, nenhuma atração é esperada quando as moléculas de superfície das substâncias atraentes são separadas por distâncias maiores que $0,7 \mathrm{~nm}(0,0007 \mu \mathrm{m})$ (ANUSAVICE et al., 2013). Além do contato íntimo entre as superfícies, seguem discriminados abaixo outros fatores relevantes ao processo de adesão do pó às IPLs:

1. carga eletrostática sobre as superfícies envolvidas;

2. formato, tamanho, área superficial e energia livre de superfície;

3. química das superfícies envolvidas;

4. forças intermoleculares;

5. molhabilidade (capacidade de umedecimento);

Cada um desses aspectos influenciadores do mecanismo de adesão entre o pó tradicional e as IPLs serão, na ordem em que foram apresentados acima, devidamente detalhados nas próximas seções. 


\section{Carga Eletrostática sobre as Superfícies ENVOLVIDAS}

Se as partículas do pó estiverem carregadas, o valor da força atrativa de Coulomb para com a superfície das IPLs pode exceder a de outras contribuições para a adesão (ZIMON, 1982). As IPLs podem possuir alguma carga elétrica residual logo após a deposição; dessa forma, se for utilizado um pó com partículas carregadas de sinal oposto, ele será facilmente atraído pelo fragmento impresso (BLEAY et al., 2018). Essa interação carga-carga é regida pela Lei de Coulomb, e a força elétrica de atração varia com o inverso do quadrado da distância entre as cargas (HALLIDAY; RESNICK; WALKER, 1996). A figura 1 ilustra essa situação.

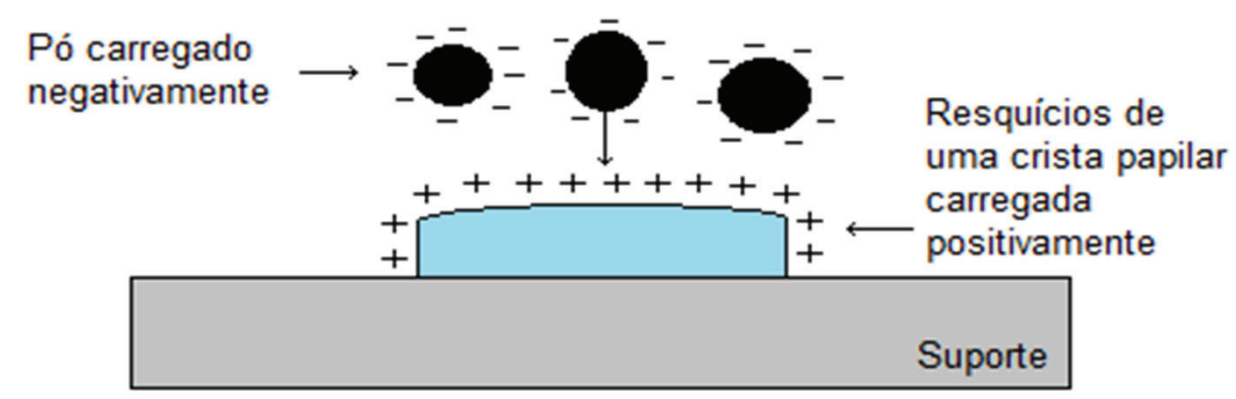

Figura 1. Diagrama esquemático mostrando a interação eletrostática entre partículas de pó carregadas negativamente e os resquícios de uma impressão da crista papilar carregada positivamente.

Embora sejam encontradas citações a respeito de trabalhos que utilizaram esse efeito elétrico para melhorar o desenvolvimento de IPLs, este não é o principal mecanismo utilizado em nenhum dos pós atualmente empregados em cenas de crime. Nesses estudos, observou-se que o contato do pincel durante o "empoamento" com a superfície tende a remover a carga estática residual sobre as linhas das IPLs, fazendo com que a revelação não produza bons resultados (SODHI ; KAUR, 2001); (BLEAY et al., 2018).

\section{Formato, Tamanho, Área Superficial e Energia LIVRE DE SUPERFÍCIE}

Áreas especializadas, tais como análise de imagens e microscopia, tradicionalmente utilizam-se de fatores de forma para descreverem nume- 
ricamente a forma de uma imagem, independentemente de seu tamanho (BERGER, 1995); (MARTÍNEZ et al., 2011). Os fatores de forma são grandezas adimensionais calculadas a partir das dimensões das partículas e seus valores variam de zero a um, quando normalizados. Um fator de forma igual a um costuma representar um caso de simetria máxima, como um círculo, esfera, quadrado ou cubo.

Um fator de forma interessante para o estudo de pós reveladores é a proporção de aparência (também conhecido por proporção de tela). Esta grandeza nada mais é do que a razão entre o maior diâmetro e o menor diâmetro ortogonal a ele $(\mathrm{Ap}=\mathrm{dmáx} / \mathrm{dmin})$ do objeto em questão (MARTÍNEZ et al., 2011). Enquanto pós granulares tendem a ser esféricos, ou possuírem baixa proporção de aparência, os pós flocados são achatados e apresentam alta proporção de aparência.

Como já mencionado, o formato da partícula pode afetar a maneira como esta adere às diferentes superfícies. Os pós granulares de baixa proporção de aparência podem rolar facilmente pela superfície, enquanto os pós flocados têm uma maior tendência a deslizar (BLEAY et al., 2018). Para o caso em que os pós ficarão sobre a superfície da crista papilar impressa, os pós flocados tendem a possuir uma maior área superficial de contato com esta, quando comparado aos pós granulares. Inevitavelmente, diferentes áreas superficiais de contatos significam diferentes interações. A figura 2 ilustra a presente situação.

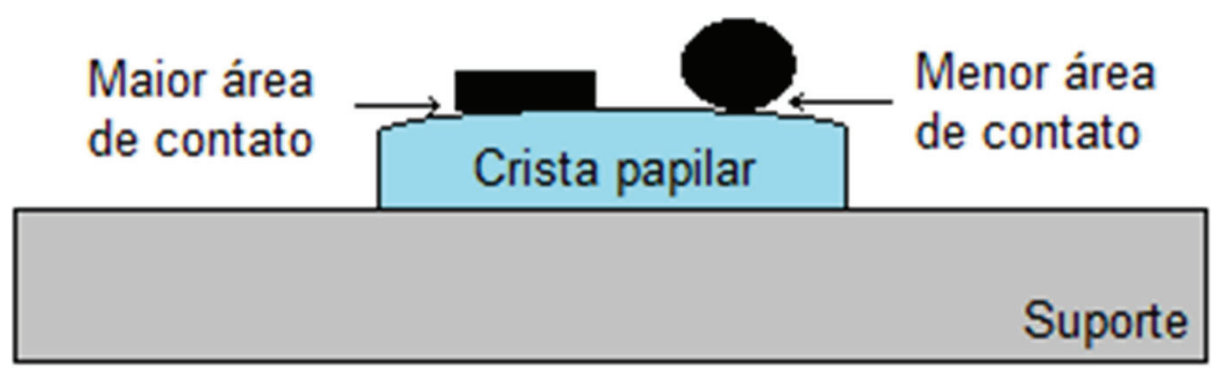

Figura 2. Diagrama esquemático mostrando a maior área de contato dos pós flocados, quando comparados aos pós granulares, com a superfície da crista papilar impressa, para o caso de os pós ficarem sobre a crista.

Os diversos modos de movimentos podem tornar mais ou menos prováveis os mecanismos de adesão (BLEAY et al., 2018), sendo que estes estão diretamente relacionados ao tamanho, ao formato da partícula e à área superficial de contato que esta possui. A figura 3 apresenta a área su- 
perficial de partículas com diferentes formatos em função do volume ocupado. Percebe-se, por exemplo, que a área superficial diminui para formas mais arredondadas de volume com mesma ordem de grandeza.

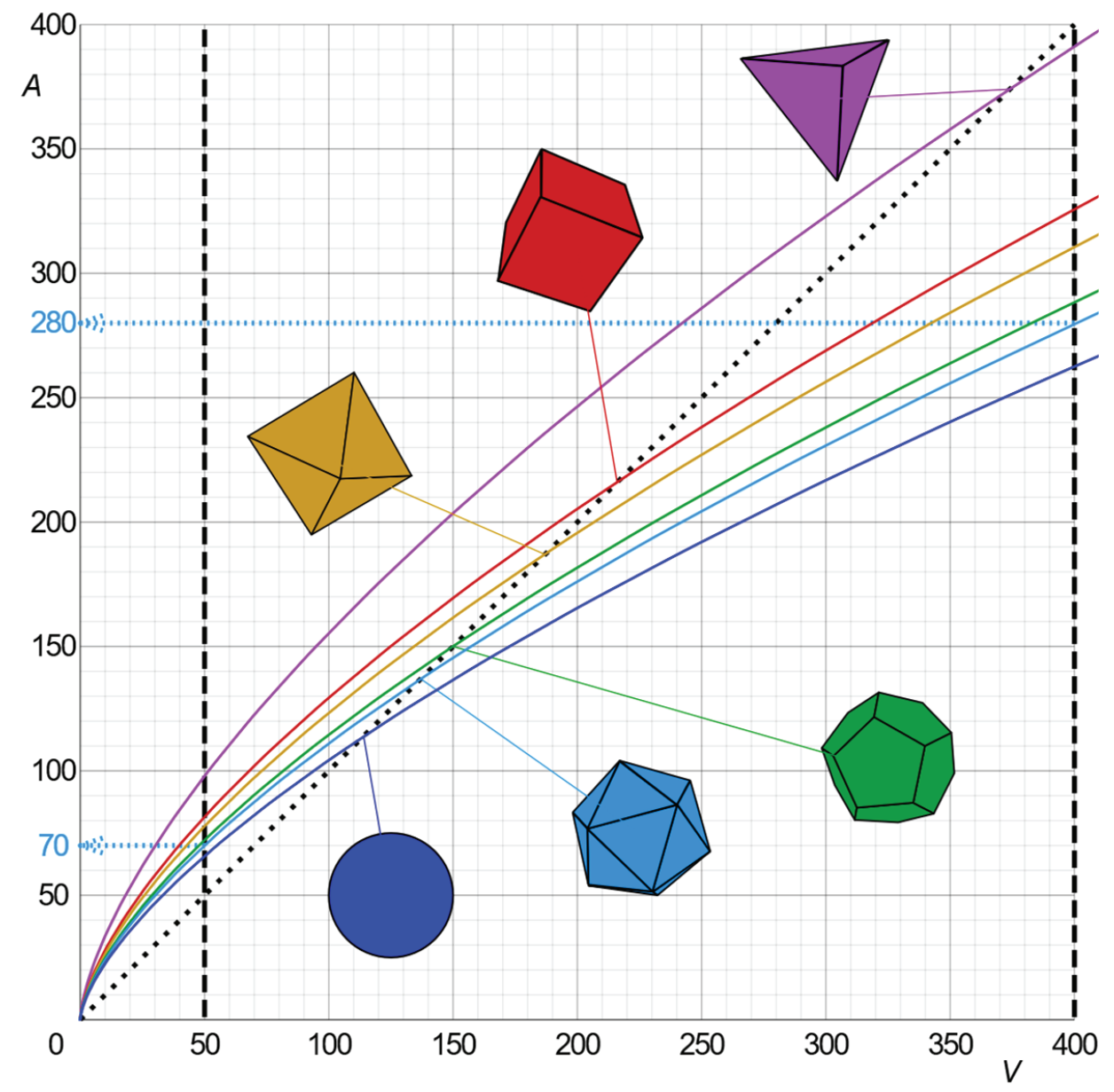

Figura 3. Gráficos da área superficial "A" em relação ao volume "V" de seis diferentes formas geométricas, mostrando que a área superficial diminui para formas mais arredondadas. As interceptações com as linhas tracejadas mostram que quando o volume aumenta $8\left(2^{3}\right)$ vezes, a área da superfície aumenta $4\left(2^{2}\right)$ vezes (CONTRIBUTORS).

Outro aspecto relevante é que quanto maior a partícula, menor sua área superficial proporcional ao próprio tamanho. Para melhor entender esta afirmação, propõe-se calcular a área superficial e o volume de uma partícula esférica qualquer e dividir um valor pelo outro. Dos ensinamentos de geometria básica, sabe-se que a área da superfície da esfera é calculada por $\mathrm{A}_{\text {esfera }}=4 \pi \mathrm{r}^{2}$, enquanto o volume da esfera é $\mathrm{V}_{\text {effera }}=4 / 3 \pi \mathrm{r}^{3}$, sendo que, em ambas as equações, r é o raio da esfera (RYAN, 2019).

Naturalmente, quanto maior o raio, maior o tamanho da partícula. Quanto maior a partícula, maior o seu volume. $\mathrm{A}$ razão $\mathrm{A}_{\text {effera }} / \mathrm{V}_{\text {esfera }}$ resultará 
na quantidade de área de superfície por unidade de volume de um objeto, no caso, da esfera. Percebe-se, a partir da equação 1, que quanto menor o raio (partículas menores), maior a razão área superficial por volume. Isso significa que uma coleção de partículas pequenas tem maior área de superfície em comparação com uma única partícula de tamanho macro que consistiria em todas as pequenas partículas colapsadas em uma única unidade.

Equação 1. Cálculo da razão entre a área superficial e o volume de uma esfera.

$$
\frac{A_{\text {esfera }}}{V_{\text {esfera }}}=\frac{4 \pi r^{2}}{\frac{4 \pi r^{3}}{3}}=\frac{3}{r}
$$

Para melhor evidenciar o crescimento da área superficial proporcional à redução do tamanho da partícula, imagina-se uma partícula de pó com o volume de $1 \mathrm{~cm}^{3}$, em forma de cubo, sendo dividida em cubos menores. À medida que a partícula é diminuída, a área total da superfície da coleção de partículas formadas se torna cada vez maior. A tabela 1 mostra que a área superficial de um único cubo de volume igual a $1 \mathrm{~cm}^{3}$ é 6,0 $\mathrm{cm}^{2}$, enquanto a área superficial de uma coleção de cubos $\left(10^{21}\right)$ formada a partir da divisão de um cubo de volume igual a $1 \mathrm{~cm}^{3}$ é de $6,0 \times 10^{7}$. Dito de outra forma, neste caso, ocorreu um crescimento de dez bilhões de vezes na área superficial total.

TABELA 1. Variação de parâmetros da partícula com o tamanho da partícula (RAMOTOWSKI, 2012).

\begin{tabular}{ccccc}
\hline $\begin{array}{c}\text { Número total de } \\
\text { cubos gerados } \\
\text { a partir de um } \\
\text { cubo de } 1 \mathrm{~cm}^{3}\end{array}$ & $\begin{array}{c}\text { Soma da área } \\
\text { superficial } \\
\text { de todos os } \\
\text { cubos gerados } \\
\left(\mathrm{cm}^{2}\right)\end{array}$ & $\begin{array}{c}\text { Volume de } \\
\text { cada cubo } \\
\left(\mathrm{cm}^{3}\right)\end{array}$ & $\begin{array}{c}\text { Comprimento } \\
\text { de cada lado do } \\
\text { cubo }(\mathrm{cm})\end{array}$ & $\begin{array}{c}\text { Área super- } \\
\text { ficial de cada } \\
\text { cubo }\left(\mathrm{cm}^{2}\right)\end{array}$ \\
\hline 1 & 6,0 & 1,0 & 1,0 & 6,0 \\
\hline $10^{3}$ & 60 & $1,0 \times 10^{-3}$ & 0,1 & 0,060 \\
\hline $10^{6}$ & 600 & $1,0 \times 10^{-6}$ & 0,01 & $6,0 \times 10^{-4}$ \\
\hline $10^{9}$ & $6,0 \times 10^{3}$ & $1,0 \times 10^{-9}$ & $10^{-3}$ & $6,0 \times 10^{-6}$ \\
\hline $10^{12}$ & $6,0 \times 10^{4}$ & $1,0 \times 10^{-12}$ & $10^{-4}$ & $6,0 \times 10^{-8}$ \\
\hline $10^{15}$ & $6,0 \times 10^{5}$ & $1,0 \times 10^{-15}$ & $10^{-5}$ & $6,0 \times 10^{-10}$ \\
\hline $10^{18}$ & $6,0 \times 10^{6}$ & $1,0 \times 10^{-18}$ & $10^{-6}$ & $6,0 \times 10^{-12}$ \\
\hline $10^{21}$ & $6,0 \times 10^{7}$ & $1,0 \times 10^{-21}$ & $10^{-7}$ & $6,0 \times 10^{-14}$ \\
\hline
\end{tabular}


As regiões superficiais são particularmente interessantes devido à instabilidade termodinâmica que apresentam (RAGONE, 1995), o que favorece a reatividade química e as interações intermoleculares. Por possuírem maior energia livre, essas regiôes se tornam altamente reativas e, consequentemente, particularmente favoráveis ao fenômeno da adesão. A diferenciação de propriedades entre a superfície dos materiais e seu interior advém do fato de os átomos superficiais interagirem com um número menor de átomos vizinhos, fazendo com que um excesso de energia total seja gerado na superfície (KEHRWALD, 2009) (Figura 4).

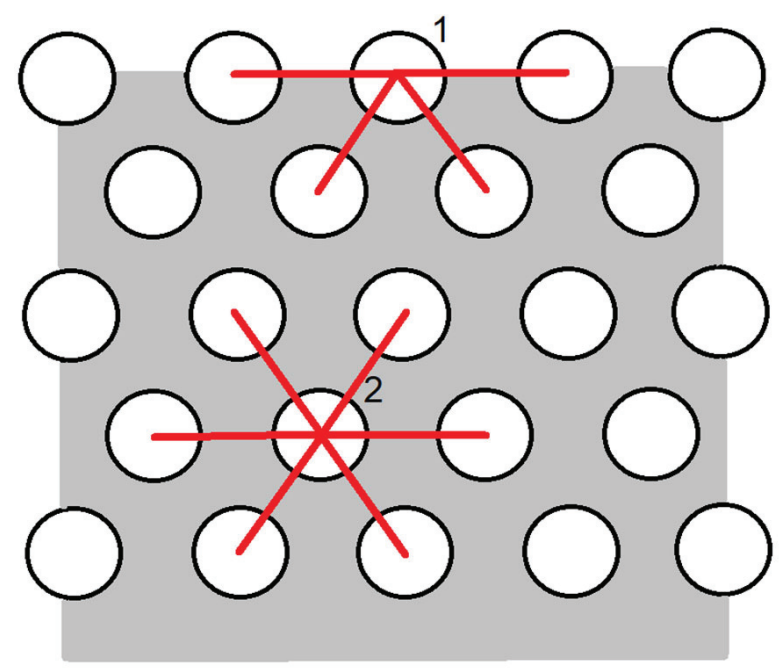

Figura 4. Diagrama esquemático mostrando o menor número de interações executadas entre os átomos superficiais, representado pelo átomo 1, em comparação com os átomos no interior do material, representados pelo átomo ${ }^{2}$.

Outra possível contribuição para esse efeito pode ser encontrada no fato de que a fração de átomos na superfície de uma partícula de pó (em comparação com os incorporados em sua parte interna/nuclear) aumenta à medida que o tamanho médio das partículas de pó diminui ${ }^{2}$ (RAMOTOWSKI, 2012). Acrescente-se a isso, a possibilidade de os átomos de superfície serem distribuídos anisotropicamente (SOMORJAI; LI, 2010), pois não estão perfeitamente presos à malha, como os átomos do interior. Além de mais reativos, por não necessariamente obedecerem à mesma simetria de rede e não completarem todas as interações com os átomos do interior da malha, os átomos da superfície se apresentam em maior quantidade à medida que o tamanho médio das partículas do pó são reduzidas.

2 As nanopartículas, por exemplo, exibem importantes propriedades que surgem devido ao tamanho que possuem, e um fator de extrema importância é que essas propriedades não são percebidas quando o mesmo material se apresenta em tamanho macroscópico. 
Essa energia advinda das peculiaridades supracitadas afetas às superfícies é denominada de energia livre de superfície. De certa forma, essa energia é a responsável pela interação com outras superfícies (BERG, 1993) e, consequentemente, pelos fenômenos de adesão e molhabilidade (KEHRWALD, 2009). Pensando na interação pó-IPLs, a energia livre de superfície se relaciona com a força de atração que a superfície das partículas de pó exercerá sobre os resquícios presentes nas impressões provenientes das cristas papilares.

É importante mencionar que a energia de superfície dos materiais gera uma tensão superficial sobre as respectivas superfícies ${ }^{3}$. Para os líquidos, a tensão superficial é bastante evidente e se configura em uma espécie de força que age de forma a se opor a qualquer aumento na área superficial. Para aumentar a área superficial de um líquido, é necessário realizar um trabalho sobre ele, fazendo com que este se comporte como uma pele que está sendo esticada, daí o termo "tensão superficial" (PASHLEY; KARAMAN, 2004); (KLEMEN, 2005).

É essa tensão superficial que permite, por exemplo, que alguns insetos caminhem livremente sobre a superfície da água de lagoas ou rios, pois a deformação local propiciada pelo peso do inseto não é suficiente para romper a tensão superficial da água (KLEMEN, 2005). Os pós reveladores precisam ser fabricados de forma a romperem a tensão superficial (coesão) dos resquícios líquidos presentes nas cristas papilares impressas. Para tanto, devem possuir alta energia livre de superfície para viabilizar a realização de trabalho sobre a tensão superficial dos líquidos presentes nas cristas papilares impressas e, consequentemente, viabilizar que as forças de adesão sólido-líquido superem a de coesão (líquido-líquido). Este assunto será retomado com mais detalhes na seção sobre molhabilidade.

Em suma, tanto o formato como o tamanho da partícula do pó revelador influenciam a maneira como esse interage com as diferentes superfícies, seja porque há uma maior ou menor tendência a rolar ou deslizar,

3 Em razão a igualdade de grandezas, tensão superficial e energia livre de superfície são tratadas como propriedades equivalentes, entretanto essa analogia concorda para líquidos e diverge para sólidos (KEHRWALD, 2009). Pensar em tensão superficial remete a força por unidade de comprimento e isso significa deformação na superfície. Em substâncias líquidas, a mobilidade atômica é maior e com o aumento da área superficial ocorre a manutenção das características superficiais em razão da vinda de átomos do interior à superfície. Em sólidos, a mobilidade atômica é menor e o aumento da área superficial acabaria sendo interpretado como deformação plástica (RAGONE, 1995). 
seja porque altera-se a área superficial - e consequentemente a energia livre de superfície - de interação entre o pó e as cristas papilares impressas e/ou superfícies. Além disso, o tipo de elemento que compõe as superfícies envolvidas na interface - a química das superfícies pó-crista papilar impressa - é outro fator de extremada relevância nesse processo.

\section{Química das Superfícies Envolvidas}

Alterar a química das superfícies envolvidas no processo de revelação de IPLs pela técnica de empoamento fará com que a interação entre a partícula do pó e o meio ao qual ela tende a se aderir seja alterada, pois cada tipo de molécula possui características próprias. Reações químicas, forças intermoleculares e interações lipofílicas podem passar a existir devido a pequenas mudanças na composição química das superfícies de interação pó-crista papilar impressa.

A perícia papiloscópica emprega reveladores que atuam a partir de compostos presentes em cada uma das frações de constituintes da impressão papilar (LOBO, 2019). Apesar de a composição das IPLs poder variar de acordo com o estilo de vida do indivíduo que as geram (RAMOTOWSKI, 2012), alguns componentes básicos de origem endógena estão sempre presentes. A partir das glândulas écrinas, presentes por todo o corpo, são excretados uma série de compostos, como água, sais inorgânicos, ureia, aminoácidos, proteínas, ácido úrico, ácidos láticos e açúcares. Já os esqualenos, triglicerídeos, ácidos graxos e fosfolipídios são oriundos de glândulas sebáceas, as quais não estão presentes nas palmas das mãos e solas dos pés, mas em outras regióes comumente tocadas pelas pontas dos dedos, como a face e o cabelo (GIROD et al., 2012).

As IPLs têm sua composição alterada à medida que envelhecem. A água, por exemplo, paulatinamente evapora, deixando para trás uma densa e complexa mistura (CHAMPOD et al., 2016), na forma de emulsão (BUMBRAH; SODHI; KAUR, 2019). Estes vestígios permanecem por bastante tempo na superfície do substrato (a menos que sejam removidos por meio de contato físico - como esfregões), uma vez que as superfícies não porosas e semiporosas não os absorvem. Impressões papilares recentes serão reveladas, em primazia, devido a interações com a água; contudo, impressões envelhecidas, serão reveladas principalmente a partir de inte- 
rações com outros componentes (gorduras, ceras e hidrocarbonetos de cadeia longa).

De uma forma geral, para os casos em que as marcas papilares apresentem baixa viscosidade (muita água), os líquidos presentes precisam molhar a superfície do pó, aumentando a área superficial de contato (este assunto será melhor detalhado na seção sobre molhabilidade) e, consequentemente, favorecendo a adesão do pó à crista papilar impressa. Entretanto, quanto maior a presença de elementos gordurosos nas marcas papilares, maior a viscosidade destes resquícios (menos água). Um meio de alta viscosidade pode fazer com que a partícula do pó desacelere seu rolamento e fique presa na marca papilar (BLEAY et al., 2018).

Para as impressões recentes, o pó é um dos reveladores mais recomendados; para as envelhecidas, recomenda-se a utilização de técnicas mais sensíveis, tais como o revelador físico ${ }^{4}$ (CHAMPOD et al., 2016). Há na literatura, entretanto, iniciativas que aumentam a atratividade do pó com os elementos remanescentes nos fragmentos papilares envelhecidos, tendo já sido demonstrado que alguns revestimentos de superfície influenciam a eficácia dos pós (magnéticos ou não) durante a revelação de IPLs (BLEAY et al., 2018).

A presença de revestimentos de ácido esteárico (uma gordura saturada de cadeia longa) em pós flocados de alumínio, por exemplo, favorece o surgimento de interações lipofílicas entre o revestimento de ácido esteárico e os ácidos graxos comumente encontrados nas impressões papilares (JAMES et al., 1991). Contudo, impende mencionar que otimizar as propriedades dos diferentes materiais se configura em uma área de estudos relativamente nova, de alta complexidade (denominada de engenharia de superfície) e que abrange iniciativas interdisciplinares da engenharia mecânica, ciência dos materiais, física e outras disciplinas (RICKERBY; MATTHEWS, 1991); (KEHRWALD, 2009).

Muitos são os fatores que influenciam o mecanismo de adesão seletiva do pó às cristas impressas. Mencionar que a superfície química da partícula do pó influencia nesse processo é o mesmo que afirmar que ou-

4 O revelador físico é um processo químico que envolve a deposição preferencial de prata nas linhas das marcas papilares. Acredita-se que a presença de constituintes sebáceos auxilia nesta deposição (EUROPEAN NETWORK OF FORENSIC SCIENCE INSTITUTES, 2015). 
tras interações passarão a (ou deixarão de) existir a depender dos grupos químicos funcionais disponíveis ou do tipo de plano cristalino da rede espacial presente na interface entre as superfícies envolvidas na adesão (ANUSAVICE et al., 2013). Um desses aspectos, por exemplo, é a interação intermolecular que desempenha papel importante na adesão do pó à crista papilar impressa.

\section{FORÇAS INTERMOLECULARES}

As forças intermoleculares são, em sua maioria, de natureza eletrostática e incluem forças de Van der Waals e ligações de hidrogênio. Em líquidos, por exemplo, as moléculas se agregam a outras moléculas por interações intermoleculares. Tais interações são mais fracas que as intramoleculares (que mantêm os átomos juntos dentro de uma molécula), mas desempenham papel importante em diversos fenômenos, tais como: adesão; tensão superficial; adsorção física; umedecimento; propriedades de gases, líquidos e filmes finos; floculação de partículas em líquidos; entre outros (ISRAELACHVILI, 1992).

As transições de fases são influenciadas pelas forças intermoleculares. Por exemplo, a mudança do estado gasoso para o líquido, quando um gás qualquer se condensa, é acompanhada de uma contração de volume, o que evidencia a existência de forças de coesão entre as moléculas envolvidas na mudança de estado. Essas forças são as já mencionadas forças intermoleculares.

Considere duas moléculas na presença de um campo elétrico. Este campo gerará, pelo mecanismo da polarização, um momento de dipolo elétrico em cada molécula. Naturalmente, devido à existência de uma carga líquida advinda da polarização, as moléculas se atrairão. Essas forças de coesão foram propostas originalmente por Debye e Keeson, após Van der Waals ter demonstrado a existência de um potencial de interação atrativo entre dois átomos em seu trabalho sobre a equação de estado de gases e líquidos (trabalho que lhe rendeu o Nobel de Física de 1910) (NOBEL, 1910).

Uma vez induzido o dipolo elétrico na molécula, não há mais a necessidade de um campo elétrico externo, pois o campo dos próprios 
dipolos é suficiente para gerar a atração entre elas. Contudo, percebeu-se que até mesmo moléculas esfericamente simétricas no estado fundamental estão sujeitas a tais forças de coesão, mesmo que não exista um campo elétrico externo com intensidade suficiente para polarizá-las.

Fritz London (1930) demonstrou que há uma força geral de atração entre duas moléculas (ou átomos) mesmo que nenhuma possua um momento de dipolo permanente. Um átomo apolar, como o Hélio, apresenta um movimento interno de cargas que pode induzir momentaneamente um dipolo. Essas flutuações de curta duração causam a formação temporária de polos induzidos em moléculas (ou átomos) adjacentes, sejam estas polares ou não polares (HUNTER, 2001); (ATKINS; PAULA, 2008). A interação resultante entre os dois dipolos gera uma força atrativa entre os dois átomos, e o tempo médio dessa força é finito (ISRAELACHVILI, 1992).

Aproximados dois átomos (ou moléculas) nestas circunstâncias, os dipolos induzidos agem de forma que o resultado é uma atração líquida entre eles, evidenciando a universalidade dessa força intermolecular (ISRAELACHVILI, 1992); (HUNTER, 2001). Apesar da possibilidade dessa força de dispersão também ser repulsiva, em geral, o somatório das várias interações entre os diversos átomos envolvidos tende a ser atrativo. A figura 5 evidencia que essa força aproxima os átomos; contudo, cabe registrar que ela também tende a proporcionar um alinhamento mútuo entre eles.

a)
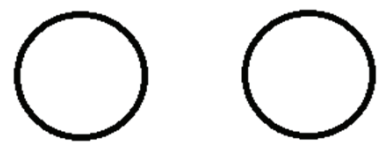

b)
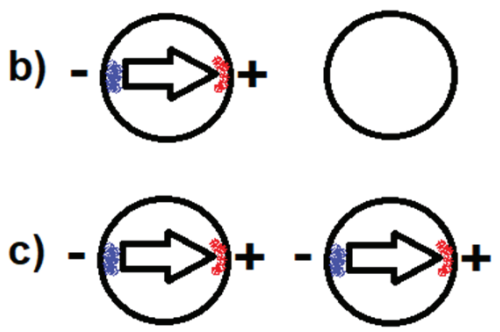

Figura 5. Diagrama esquemático mostrando dois átomos de hélio em momentos diferentes: (a) os dois átomos, momentaneamente, sem dipolos induzidos; (b) o átomo da esquerda apresenta um dipolo instantâneo; (c) um dipolo instantâneo induz um dipolo no átomo da direita, e os dois dipolos interagem.

A força atrativa entre a partícula do pó e os resquícios papilares 
também pode estar associada a interações intermoleculares de dipolo (polaridades induzidas ou permanentes) criadas pelos campos elétricos de átomos ou moléculas vizinhas. Essas forças incluem interações de dipolo permanente com dipolo permanente (Keesom, componente eletrostático), interações de dipolo permanente com dipolo induzido (Debye, componente de polarização), e interações de dipolo induzido com dipolo induzido (London, componente eletrodinâmico) (GOODWIN, 2004); (ATKINS; PAULA, 2008). (HOLWILL, 2019), conforme sintetizado pela figura 6 .

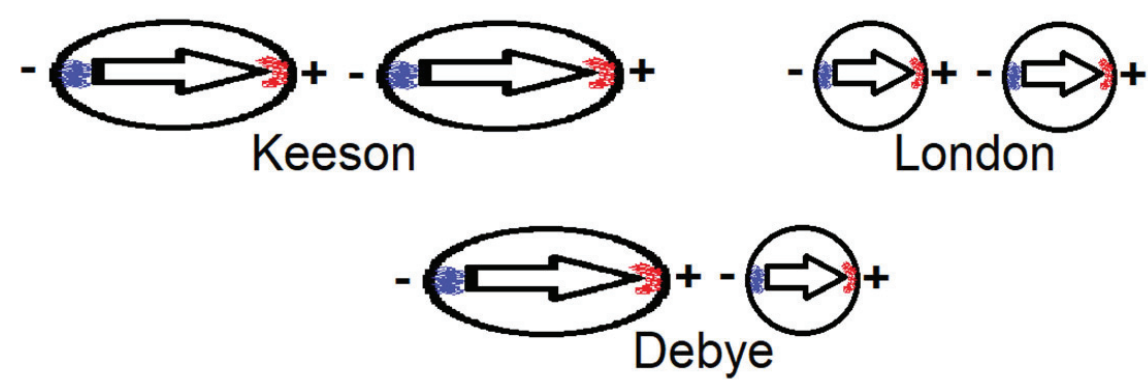

Figura 6. Diagrama esquemático das três forças de van der Waals. As elipses e círculos indicam dipolos permanentes e induzidos, respectivamente. As forças de Keesom atuam entre dipolos permanentes, as forças de London agem entre dipolos induzidos e as forças de Debye, entre dipolos permanentes e induzidos.

Todas essas três interações, comumente chamadas de interações ou forças de Van der Waals, tendem a ser mais facilmente percebidas quanto maiores os átomos (ou moléculas) envolvidos. Átomos maiores tendem a ser mais polarizáveis que os menores porque seus elétrons externos são menos fortemente ligados ao núcleo e, portanto, mais facilmente perturbados pelos campos elétricos de moléculas adjacentes (ATKINS; PAULA, 2008).

Para duas partículas de dimensões moleculares separadas pela distância "R", as interações de Van der Waals são de curto alcance (de forma que a energia de atração possui uma dependência de 1/R ${ }^{6}$ ) (PASHLEY; KARAMAN, 2004); (RAMOTOWSKI, 2012). Entretanto, à medida que as partículas aumentam (aproximando-se de um plano em relação à partícula menor ou mesmo de dois planos), as interações se tornam mais amplas (HUNTER, 2001) e não seguem uma lei de interação simples (ISRAELACHVILI, 1992). Por isso, muitas vezes, encontra-se na literatura especializada a menção às interações de Van der Waals (ou forças de Hamacker) de longa distância (algo em torno de 10nm), particular- 
mente importantes em amostras coloidais (PASHLEY; KARAMAN, 2004).

Já as ligações de hidrogênio são interações dipolo-dipolo especialmente fortes entre moléculas que têm hidrogênio $(\mathrm{H})$ ligado a um átomo altamente eletronegativo, como oxigênio $(\mathrm{O})$, nitrogênio $(\mathrm{N})$ ou Flúor $(\mathrm{F}) . \mathrm{O}$ átomo $\mathrm{H}$ parcialmente carregado positivamente resultante em uma molécula (o doador da ligação de hidrogênio) pode interagir fortemente com um átomo que possua pelo menos dois elétrons de valência, tal qual $\mathrm{O}, \mathrm{N}$ ou $\mathrm{F}$ parcialmente carregado negativamente em moléculas adjacentes (o aceitador da ligação de hidrogênio) (ATKINS; PAULA, 2008).

Via de regra, quando presente, a ligação hidrogênio domina todas as outras interações moleculares. As propriedades da água líquida e da água sólida, por exemplo, são dominadas pela ligação hidrogênio entre as moléculas de $\mathrm{H}_{2} \mathrm{O}$. A estrutura do DNA é crucialmente dependente da intensidade das ligações hidrogênio entre os pares de bases (ATKINS; PAULA, 2008).

A existência de interações intermoleculares entre o pó revelador e os resquícios presentes nas marcas papilares podem ser determinantes na revelação do fragmento de IPL, uma vez que tendem a facilitar a fixação do pó sobre as cristas papilares impressas. Registre-se, ainda, que as forças intermoleculares guardam estreita relação com o surgimento de forças capilares e no umedecimento, interações estas que desempenham importante papel no processo de adesão seletivo do pó revelador às cristas papilares impressas.

\section{Molhabilidade (Capacidade de Umedecimento)}

Cada líquido escoa de forma única sobre as superfícies. A título de exemplo, imagine um experimento em que uma gota de determinado líquido seja colocada sobre a superfície horizontal de um vidro qualquer. Caso essa gota não se espalhe, diz-se que não ocorreu molhamento; contudo, o mesmo não necessariamente ocorre para gotas de diferentes líquidos. À medida que o mesmo experimento é repetido para outros líquidos, é bem provável que seja observado espalhamento da gota em 
alguns casos. Sobre estes líquidos, diz-se que possuem um melhor molhamento (uma maior molhabilidade ou capacidade de umedecimento).

Molhabilidade refere-se à manifestação macroscópica da interação intermolecular entre líquidos e sólidos (BERG, 1993). A molhabilidade resulta do balanço energético entre as forças coesivas do líquido ${ }^{5}\left(\mathrm{Wc}=2 \gamma_{1}\right)$ e as forças adesivas sólido-líquido (Wa $=\gamma_{1}+\gamma_{\mathrm{s}}+$ $\left.\gamma_{\mathrm{s}}\right)^{6}$ (KEHRWALD, 2009). A resultante dessa competição pode ser estimada pelo ângulo de contato medido a partir do equilíbrio, na direção horizontal, das tensões interfaciais das fases envolvidas (sólido-líquido, líquido-vapor e vapor-sólido, conforme figura 7) (SHAW, 1975); (NEUMANN et al., 2011).

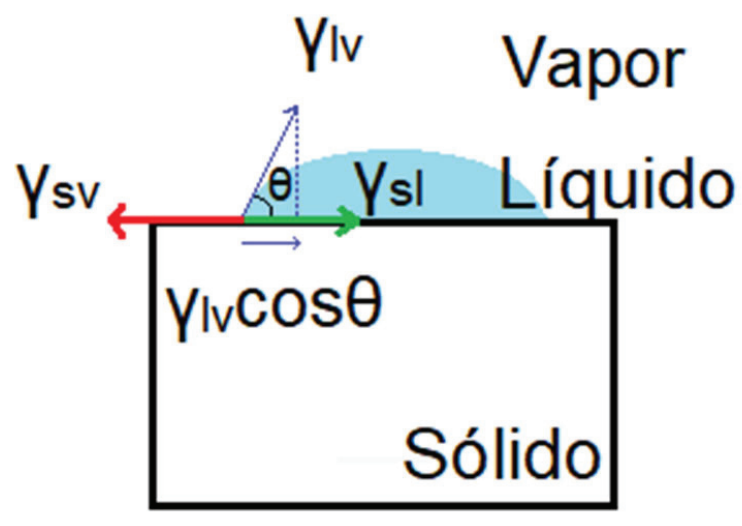

Figura 7. Diagrama esquemático das relações entre as energias interfaciais nas interfaces líquido-vapor $\left(\gamma_{\mathrm{lv}}\right)$, sólido-líquido $\left(\gamma_{\mathrm{s} \mid}\right)$ e sólido-vapor $\left(\gamma_{\mathrm{sv}}\right)$ em relação ao ângulo de contato em equilíbrio.

Essa relação de equilíbrio é conhecida como equação de Young (Equação 2). A equação de Young contém apenas duas quantidades mensuráveis, o ângulo de contato $\theta$ e a tensão interfacial líquido-vapor, $\gamma_{\mathrm{lv}}$. Para determinar $\gamma_{\mathrm{sv}}$ e $\gamma_{\mathrm{sl}}$, deve-se buscar uma relação adicional entre essas quantidades. Fundamentalmente, as tensões líquidas $\gamma_{\mathrm{lv}}$ e sólidas $\gamma_{\mathrm{sv}}$ refletem a força das interaçóes moleculares nos respectivos materiais. Portanto, é razoável esperar que a tensão interfacial sólido-líquido $\gamma_{\mathrm{sl},}$ refletindo interações cruzadas entre as duas fases, possa ser derivada em termos de $\gamma_{\mathrm{lv}}$ e $\gamma_{\mathrm{sv}}$. Essa relação $-\gamma_{\mathrm{sl}}=\mathrm{f}\left(\gamma_{\mathrm{lv}}, \gamma_{\mathrm{sv}}\right)$-, juntamente com a equação de Young (Equação 2), permite de fato a determinação de $\gamma$ sv e

5 Para dois meios diferentes, o trabalho é rotulado como trabalho de adesão (Wa); para dois meios idênticos, trabalho de coesão (Wc) (KLEMEN, 2005).

$6 \gamma$ representa a tensão superficial do líquido, sólido e da interface sólido-líquido, respectivamente aos índices 1 , s e sl. 
$\gamma_{\mathrm{sl}}$ a partir de medições de $\gamma_{\mathrm{lv}}$ e $\theta$ (NEUMANN et al., 2011).

Equação 2 - Equação de Young, onde $\theta$ é o ângulo de contato, $\gamma_{\mathrm{lv}}$ é a tensão superficial da interface líquido-vapor, $\gamma_{\mathrm{sv}}$ é a tensão superficial da interface sólido-vapor e $\gamma_{\mathrm{sl}}$ é a tensão superficial da interface sólido-líquido (O’BRIEN, 1967).

$$
\gamma_{\mathrm{lv}} \cos \theta=\gamma_{\mathrm{sv}}-\gamma_{\mathrm{sl}}
$$

Em termos mais simples, a capacidade de um líquido se espalhar sobre uma superfície sólida recebe o nome de molhamento. Para estimá-lo, pode-se utilizar o parâmetro de espalhamento "S" (Equação 3) - referência que permite distinguir se o molhamento é total ou parcial (DAVIES et al., 1966). Há uma relação entre o parâmetro de espalhamento e o ângulo de contato medido nas interfaces envolvidas (equação de Young).

Equação 3 - Equação de espalhamento, onde $\mathrm{W}_{\mathrm{a}}=\gamma_{1}+\gamma_{\mathrm{s}}+\gamma_{\mathrm{sl}}$ representa as forças adesivas na interface sólido-líquido e $\mathrm{W}_{\mathrm{c}}=2_{\gamma \mid}$, as forças coesivas do líquido.

$$
\mathrm{S}=\mathrm{W}_{\mathrm{a}}-\mathrm{W}_{\mathrm{c}}
$$

Quando o trabalho de adesão $\left(\mathrm{W}_{\mathrm{a}}\right)$ supera o trabalho de coesão $\left(W_{c}\right)$, o parâmetro de espalhamento se torna positivo, o ângulo de contato atinge valor zero e o molhamento é total. Caso o trabalho de coesão $\left(\mathrm{W}_{\mathrm{c}}\right)$ do líquido for maior que o trabalho de adesão sólido/líquido $\left(\mathrm{W}_{\mathrm{a}}\right)$, o parâmetro de espalhamento se torna negativo e, macroscopicamente, visualiza-se uma gota formando um ângulo $\theta$ com a superfície sólida, fenômeno conhecido como molhamento parcial (KEHRWALD, 2009) (figura 8).

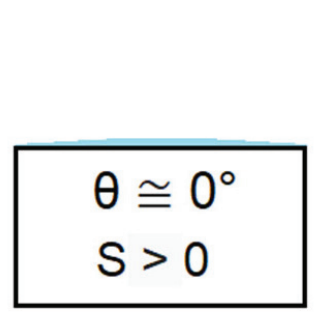

a)

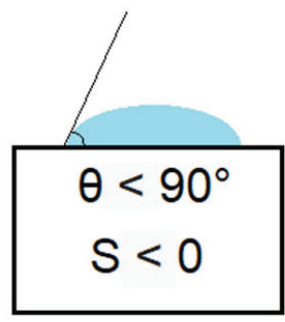

b)

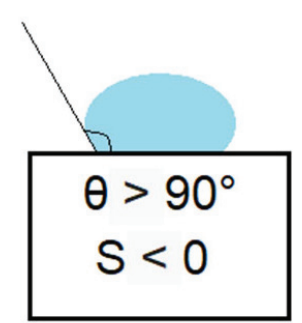

c)

Figura 8. Diagrama esquemático evidenciando: a) molhamento total; b) molhamento parcial por líquido molhante; c) molhamento parcial por líquido não molhante.

O valor do ângulo $\theta$ divide o molhamento parcial em duas novas classes: líquido molhante $\left(\theta<90^{\circ}\right)$ e líquido não molhante $\left(\theta>90^{\circ}\right)$. Através desse limiar do ângulo de contato, os materiais sólidos recebem 
uma classificação pertinente ao líquido que está em contato direto com sua superfície. Em situações nas quais a água é o líquido atuante, as superfícies são classificadas como hidrofílicas, se o ângulo de contato é inferior a $90^{\circ}$, e hidrofóbicas, para valores superiores a $90^{\circ}$ (KEHRWALD, 2009).

A adesão da partícula do pó revelador ao líquido molhante das cristas papilares impressas, então, depende do balanço energético entre as forças adesivas da interface pó-crista papilar impressa e as forças coesivas do líquido das cristas papilares impressas. Quanto maiores as forças adesivas (e menores as coesivas), mais interessante para a fixação preferencial do pó revelador sobre os resquícios papilares.

Como mencionado na seção "Formato, tamanho, área superficial e energia livre de superfície”, maximizar a área superficial (aumentar a irregularidade) da partícula do pó revelador levará a um aumento da energia livre de superfície e, consequentemente, maior será a interação entre o pó e os resquícios provenientes das cristas papilares impressas (adesão).

Portanto, os pós reveladores precisam ser cuidadosamente fabricados de sorte a favorecerem a adesão pó-crista papilar impressa e, se possível, reduzirem a coesão do líquido das cristas papilares impressas (tensão superficial). Sendo as forças de adesão mais intensas que as coesivas, as microfissuras presentes no pó revelador serão devidamente molhadas e, consequentemente, uma melhor adesão mecânica pó-crista papilar impressa ocorrerá, pois a capacidade de molhar o substrato sólido é o contribuinte dominante na ligação adesiva (ANUSAVICE et al., 2013).

Em outros termos, a engenharia dos pós reveladores precisa ser tal que permita que esses possuam a energia livre de superfície necessária para viabilizar a realização de trabalho sobre a tensão superficial (coesão) dos líquidos presentes nas cristas papilares impressas, o que se configurará em um molhamento total da superfície do pó (parâmetro de espalhamento positivo e ângulo de contato de valor zero) e, consequentemente, na efetiva adesão pó-crista papilar impressa.

Se a energia livre de superfície não for suficientemente grande a ponto de realizar um trabalho sobre a tensão superficial (coesão) dos líquidos presentes nas cristas papilares impressas (as forças de adesão só- 
lido-líquido não superaram as forças de coesão líquido-líquido), o líquido molhará apenas parcialmente a superfície sólida do pó (parâmetro de espalhamento negativo), restando em uma adesão tanto mais desprezível quanto maior o ângulo de contato formado.

Impende ainda mencionar que a prática pericial permite perceber que à medida que o pó revelador vai sendo reutilizado ${ }^{7}$, passa a ser menos efetivo na revelação de impressões papilares. Apesar disso, inexistem estudos que comprovem que quanto mais velho e mais reutilizado o pó for, mais difícil revelar impressões papilares com ele. Uma possível explicação reside na redução da energia livre de superfície do pó à medida que impurezas são a ele acrescentadas (devido à reutilização) (ANUSAVICE et al., 2013), prejudicando o umedecimento do pó pelos líquidos presentes nas cristas papilares impressas.

Outro aspecto que pode influenciar na adesão do pó às cristas papilares impressas são as forças capilares (BLEAY et al., 2018). Se uma gota de água é introduzida entre duas placas de vidro antes de serem pressionadas juntas, é encontrada uma dificuldade considerável na separação das duas placas (se comparada à situação em que as mesmas duas placas são pressionadas juntas sem a gota de água entre elas). Isso é resultado da ação capilar de forças atrativas intermoleculares entre a água e as placas de vidro (KLEMEN, 2005).

A ação capilar, fenômeno em que a superfície de um líquido é observada elevada ou deprimida quando entra em contato com um sólido, pode ser explicada considerando os efeitos de duas forças opostas, como visto anteriormente: adesão, a força atrativa entre as moléculas do líquido e as do recipiente sólido; e coesão, a força atrativa entre as moléculas do líquido. A adesão proporciona, por exemplo, que a água molhe um recipiente de vidro e, portanto, faz com que a superfície da água suba perto das paredes do recipiente (KLEMEN, 2005).

Em atmosferas com umidade relativa superior a 70\%, o aumento observado na adesão de partículas microscópicas se deve a forças capilares (BLEAY et al., 2018) (figura 9). Soprar lentamente ar quente e úmi-

7 No Brasil é bastante comum a prática de devolver para o frasco original o pó revelador já utilizado em procedimentos periciais (mas que não aderiu às cristas papilares impressas e ficou em excesso sobre o suporte). Tal prática faz frente à escassez de recursos, mas permite que paulatinamente o pó se misture a impurezas diversas. 
do pode ser um meio de melhorar a eficácia dos pós reveladores para revelar fragmentos papilares latentes que possam ter secado. Pensa-se que essa prática reumidifica a marca papilar e aumenta a probabilidade desse mecanismo de adesão (BLEAY et al., 2018).

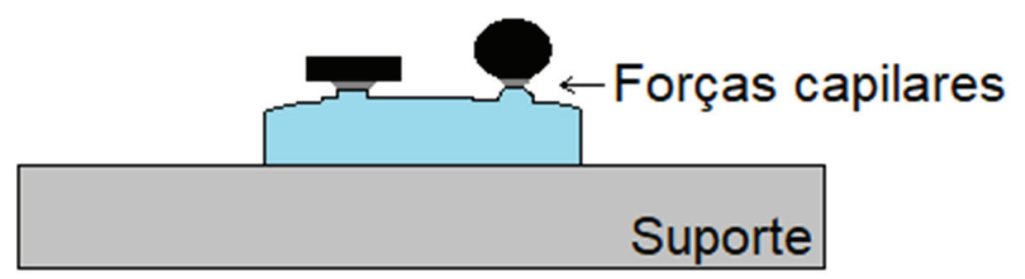

Figura 9. Diagrama esquemático mostrando a ação de forças capilares sobre as partículas do pó devido à reumidificação da crista papilar impressa.

\section{Tipos de Pós REVELADORES}

\section{Pós Comuns}

Os pioneiros na fabricação de pós reveladores usaram uma variedade de ingredientes para criar seus próprios pós, incluindo carvão, pó de chumbo, mercúrio, cinzas de charuto, ferro em pó, fuligem e talco (HOLDER et al., 2011). Muitos desses componentes eram substâncias tóxicas ou continham metais pesados inorgânicos ou compostos orgânicos aromáticos (RAMOTOWSKI, 2012).

A maioria dos pós comerciais é composta por um material aglutinante (também conhecido como transportador) para maximizar a adesão e um corante para desenvolver contraste (RAMOTOWSKI, 2012). Os fabricantes costumam rotular os pós por cor, como preto, branco, prata, cinza e assim por diante, ao invés de rotulá-los com base nos ingredientes utilizados na produção.

As partículas que servem como um bom pó de impressão digital incluem negro de fumo, talco, caulim (minério composto de silicatos hidratados de alumínio), alumínio, flocos de metal e dolomita (minério composto de carbonato de cálcio e magnésio), entre outros. Bons aglutinantes incluem pó de ferro, licopódio (vegetal), amido de milho, resina e goma arábica (espécie de resina vegetal) (HOLDER et al., 2011). 
Um dos pós reveladores mais comuns, conhecido por sua versatilidade e eficácia, é o fabricado à base de negro de fumo. Também chamado de pó granular, possui tamanho no intervalo 5-10 $\mu \mathrm{m}$ e formato irregular e suave (BLEAY et al., 2018). Quando misturado com um transportador/aglutinador, esse pó funciona em uma ampla variedade de superfícies e causa pouca pintura do substrato (pouca adesão aos sulcos) (HOLDER et al., 2011).

As misturas de negro de fumo produzem uma imagem cinza-preta escura que pode ser visualizada em superfícies coloridas variadas. Esse tipo de pó também aparecerá distinguível em superfícies pretas brilhantes, aparecendo na cor cinza clara. Curiosamente, o pó preto comum também pode ser marcado com um corante fluorescente, passando a apresentar dupla finalidade: adesão e contraste fluorescente (HOLDER et al., 2011).

Pincéis com pelo de esquilo e cerdas do tipo esfregão são as ferramentas mais utilizadas para a aplicação dos pós granulares. Os pelos de animais não atraem demasiadamente o pó, de forma que é preciso recarregar regularmente o pincel durante a pulverização (BLEAY et al., 2018), o que é particularmente interessante para um desenvolvimento cauteloso dos depósitos de fragmentos papilares, pois evita a formação de borrões.

Outros pós reveladores eficazes e amplamente utilizados são os pós flocados de metal, feitos de alumínio, zinco, cobre, latão, aço inoxidável, ferro, cobalto e níquel. Alguns dados indicam que os pós flocados são mais sensíveis que os pós granulados (HOLDER et al., 2011). Foram introduzidos para reduzir a absorção de umidade (problema comum dos pós baseados em giz ou talco) e para melhorar a durabilidade e o contraste do registro fotográfico das impressóes desenvolvidas (RAMOTOWSKI, 2012). No entanto, os pós flocados metálicos às vezes tendem a "pintar" o substrato mais do que as partículas dos pós granulares (HOLDER et al., 2011).

São fabricados a partir de partículas metálicas esféricas pela moagem de esferas em flocos. A área de superfície aumentada do floco em relação ao peso da partícula contribui para a adesão do pó (HOLDER et al., 2011). Os pós flocados disponíveis comercialmente possuem um 
diâmetro no intervalo 1-12 $\mu \mathrm{m}$, uma espessura média de $0,5 \mu \mathrm{m}$, superfície lisa e bordas irregulares (BLEAY et al., 2018).

Os flocos são revestidos com ácido esteárico (uma gordura saturada de cadeia longa), durante o processo de moagem, para evitar aglomeração (pó grudando em pó) e favorecer o surgimento de interações lipofílicas entre o revestimento de ácido esteárico e os ácidos graxos comumente encontrados nas marcas papilares latentes (BLEAY et al., 2018). O pó flocado de alumínio desenvolverá marcas de bom contraste na maioria das superfícies (sendo particularmente eficaz no vidro), mas em superfícies pintadas de prata, o pó flocado de latão é mais recomendado por gerar melhor contraste com a superfície (BLEAY et al., 2018).

O método de aplicação mais eficaz para uso com pós de flocos metálicos é o pincel de fibra de vidro (HAWTHORNE, 2009), pois esse tipo de aplicador retém o pó e o libera gradualmente, tornando-o adequado para o acúmulo progressivo de partículas de metal (HOLDER et al., 2011). Registre-se que este tipo de pincel também é bastante utilizado na aplicação de pós granulares.

\section{Pós Magnéticos}

Muitos são os pós magnéticos disponíveis. Existem pós magnéticos granulares e flocados, ambos em diferentes cores para viabilizar o melhor contraste com a superfície. São mais recomendados para superfícies lisas, texturizadas (revestidas por seladores, vernizes ou tintas) e PVC (BANDEY; GILSON, 2006), mas também funcionam bem em algumas superfícies porosas com IPLs recentes (FREITAS et al., 2019).

Os pós magnéticos granulares pretos são mais comumente usados e consistem em grandes partículas transportadoras (ou aglutinantes) magnéticas de ferro elementar (20-200 $\mu \mathrm{m}$ ) e menores partículas (pigmento) não magnéticas de óxido de ferro (Fe3O4) com tamanho de partícula no intervalo de 3 a $12 \mu \mathrm{m}$ (BLEAY et al., 2018). O pó magnético branco, embora menos eficaz que os pós granulares magnéticos cinza e prata, ainda pode ter aplicações nas revelações em superfícies escuras e texturizadas, quando o contraste é um problema (BLEAY et al., 2018).

Os pós magnéticos flocados apareceram no início dos anos 90 
(JAMES et al.; POUNDS, 1991) e são produzidos pela moagem de ferro carbonílico esférico com 3 a 5\% de ácido esteárico em um solvente apropriado para produzir um floco liso com tamanhos na faixa de 10 a $60 \mu \mathrm{m}$ (BLEAY et al., 2018). Este pó possui componente único que serve tanto como transportador como pigmento da revelação (BANDEY; GILSON, 2006).

Os pós magnéticos flocados são um pouco menos sensíveis que o pó magnético preto em superfícies texturizadas, mas podem fornecer mais contrastante em superfícies texturizadas escuras (BLEAY et al., 2018). Em comparação com o pó flocado de alumínio não magnético, os pós flocados magnéticos tiveram um desempenho melhor em superfícies mais ásperas, enquanto o pó flocado teve um desempenho ligeiramente melhor em superfícies lisas (RAMOTOWSKI, 2012).

O pó magnético é aplicado usando aplicadores que possuem um pequeno ímã na ponta. Os aplicadores magnéticos possuem a vantagem de evitar o contato direto deste com a superfície, minimizando a possibilidade de danos à IPL (RAMOTOWSKI, 2012). Embora esses pós sejam relativamente fáceis de aplicar em superfícies horizontais, o mesmo não ocorre para superfícies verticais. Nestas a aplicação é menos direta e o pó pode cair. A facilidade de aplicação em uma superfície específica deve ser levada em consideração ao selecionar o pó a ser usado (FREITAS et al., 2019). 


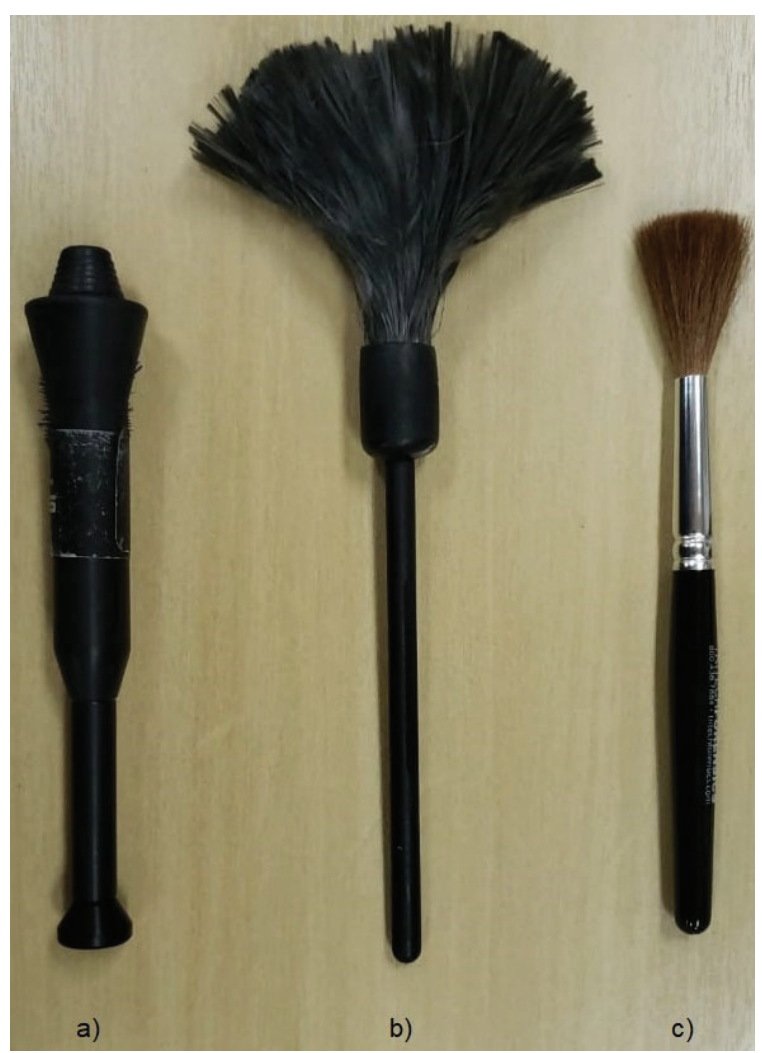

Figura 10. Aplicadores de pós reveladores: a) com ímã, utilizado para pulverizar pós magnéticos; b) de fibra de vidro, utilizado para pulverizar pós flocados de metal e c) do tipo esfregão, utilizado para pulverizar pós granulares.

\section{Pós Luminescentes}

Um bom número de pós contém derivados orgânicos naturais ou sintéticos que fluorescem ou fosforescem após a exposição à luz ultravioleta $^{8}$ ou laser (SODHI; KAUR, 2001). A maioria dos pós luminescentes atualmente disponíveis usa grandes partículas orgânicas, a exemplo do amido de milho, como transportadoras/aglutinantes para as finas partículas de pigmento fluorescente (BLEAY et al. 2018).

Apesar de existirem algumas diferenças entre fluorescência e fosforescência, a mais importante para o objeto deste estudo é que a fluorescência é uma emissão de luz que desaparece ao final da excitação, enquanto que na fosforescência a luz persiste após o final da excitação (a

8 O material luminescente impregnado às cristas papilares impressas é excitado por radiação eletromagnética de pequeno comprimento de onda - geralmente na região do ultravioleta - e passa a emitir radiação eletromagnética com comprimentos de onda maiores - geralmente na região do visível - na relaxação ("des-excitação"). Esse aumento no comprimento de onda é conhecido como deslocamento de Stokes. 
vida útil da fosforescência pode chegar até a escala de horas) (SKOOG et al.; WEST, 2006).

Os pós fluorescentes são mais comuns que os fosforescentes. Entretanto, pós fosforescentes podem ser extremamente úteis para revelação de IPLs em suportes que apresentam alguma fluorescência, pois quando a fonte de excitação é eliminada de uma amostra, a vida útil da fluorescência do suporte de fundo decairá rapidamente; no entanto, uma eventual IPL revelada com pó fosforescente continuará a brilhar. Essa diferença de tempo, embora muito pequena, permite que a interferência da fluorescência do suporte seja quase completamente eliminada (RAMOTOWSKI, 2012).

Os pós fluorescentes, que podem ser comuns ou magnéticos, encontram-se disponíveis em diferentes cores, incluindo vermelho, laranja, verde e amarelo e produzem excelentes resultados numa grande variedade de superfícies, principalmente naquelas multicoloridas que dificultam a obtenção de contraste quando periciadas com pós comuns (FREITAS et al., 2019).

Esses pós também são utilizados para melhorar as IPLs inicialmente reveladas a partir da fumigação de cianoacrilato. Além disso, são adequados para a detecção de impressões digitais latentes em superfícies difíceis, como madeira, fita adesiva e polietileno (SODHI; KAUR, 2001).

Desenvolvidos recentemente, existem pós que fluorescem na região do infravermelho (os equipamentos fotográficos devem ser sensíveis a esta radiação para que seja possível a visualização da IPL revelada) e, também, pós que possuem propriedades anti-Stokes (BLEAY et al., 2018).

Estes últimos são compostos de materiais especializados (denominados upconverters) que, quando excitados por radiação eletromagnética com maiores comprimentos de onda (energia mais baixa), como o infravermelho baixo, possibilita a absorção de vários fótons. A emissão de um único fóton ocorre em um comprimento de onda menor (energia mais alta), na região do visível. A redução no comprimento de onda é chamada de deslocamento anti-Stokes (RAMOTOWSKI, 2012). 
Os pós reveladores que utilizam materiais que apresentam fluorescência anti-Stokes são úteis quando o suporte manifesta fluorescência Stokes para a mesma faixa de comprimentos de onda utilizada para excitar reveladores fluorescentes convencionais do tipo Stokes (por exemplo, Ardrox ou amarelo básico 40), viabilizando a obtenção de contraste entre as cristas papilares impressas e o suporte (FREITAS et al., 2019).

\section{Pós de Nanotecnologia}

Nanociência, ou nanotecnologia, é a área científica que se atem a como os nanomateriais são projetados, fabricados e aplicados a usos específicos. Um exemplo de nanomaterial são as nanopartículas, que são caracterizadas por possuírem diâmetro inferior a 100 nm (RAMOTOWSKI, 2012).

Tais nanopartículas vem sendo utilizadas na fabricação de pós para revelação de IPLs. Uma dessas tecnologias envolve o uso de nanocristais semicondutores, também conhecidos como pontos quânticos. Essas partículas exibem propriedades ópticas e elétricas especiais que dependem do tamanho do nanocristal (DILAG et al., 2009). Há relatos de que os pontos quânticos fluorescem até 20 vezes mais que os pigmentos fluorescentes convencionais (JAMIESON et al., 2007). No entanto, existem sérias preocupações de saúde e segurança sobre o pó dessas nanopartículas (RAMOTOWSKI, 2012).

Há muitos estudos sendo conduzidos nesta área, principalmente diante da possibilidade de funcionalização dos pontos quânticos. Tal aspecto adicionou a possibilidade de interações químicas, e não físicas, entre resíduos das IPLs e pós de pontos quânticos. Uma visão geral e completa da tecnologia de nanopartículas para a revelação de IPLs, pode ser encontrada no livro Lee and Gaensslen's ADVANCES IN FINGERPRINT TECNOLOGHY, editado por Robert S. Ramotowski (RAMOTOWSKI, 2012).

\section{Conchusão}

A capacidade de a emulsão presente na crista papilar impressa de 
molhar a superfície sólida dos pós reveladores é influenciada por vários fatores. A ausência de contaminantes na superfície do pó e a distância entre as interfaces pó-crista papilar impressa são de particular importância. As impurezas na superfície do pó geralmente produzem uma superfície menos reativa que a superfície limpa e atrapalham no umedecimento e no contato íntimo pó-crista papilar impressa, ambos determinantes para uma efetiva adesão do pó e, consequentemente, para a revelação da marca papilar latente. Cabe registrar que quanto mais reativas as interfaces, maior a energia livre de superfície, melhor o molhamento da superfície sólida pela líquida e maior a força de adesão entre elas.

O formato, o tamanho, a área superficial e a composição química das partículas do pó também são influenciadores do processo de adesão do pó revelador às cristas papilares impressas. Todos esses interferem na reatividade das superfícies na interface pó-crista papilar impressa na medida em que influenciam a energia livre de superfície. Quanto maior a energia livre de superfície, mais interessante para o processo de adesão, pois assim, viabiliza-se a realização de trabalho sobre as forças coesivas (tensão superficial: líquido-líquido) presentes na solução líquida que compõe os resquícios papiloscópicos.

Esse balanço energético pode ser estimado pelo ângulo de contato - instituto que mensura o formato de uma gota do líquido sobre o sólido - e evidencia a capacidade de molhamento. Quando as forças adesivas superam as coesivas, diz-se que ocorreu um molhamento total (parâmetro de escoamento positivo). Neste caso, o ângulo de contato é zero. Entretanto, pode acontecer de as forças coesivas superarem as adesivas. Isso ocorrendo, ter-se-á um molhamento parcial em que a força adesiva será tanto menor quanto maior for o ângulo de contato.

Os especialistas da área, a princípio, não têm como alterar a composição dos componentes líquidos presentes nos resquícios papilares deixados em locais de crimes (exceto pela reumidificação que favorece o surgimento de forças capilares). Porém, pode-se buscar a utilização de pós reveladores cuidadosamente fabricados de forma a promover a maximização da energia livre de superfície, favorecendo, assim, as forças adesivas pó-cristas papilares impressas em detrimento das forças coesivas (líquido-líquido) internas aos resquícios das cristas papilares impressas, o que promoverá uma melhor adesão do pó aos vestígios papilares e, con- 
sequentemente, uma melhor revelação da IPL. Esse tipo de investigação, contudo, foge do escopo do presente trabalho e pode ser conduzida em estudo especificamente a ele dedicado.

O conhecimento e a aplicação correta dos princípios técnico-científicos relacionados aos procedimentos periciais de revelação de impressões papilares latentes desempenham papel de destaque na promoção de direitos e na manutenção da dignidade da pessoa humana, não apenas por, potencialmente, apresentarem suspeitos relacionados ao cometimento de determinado ato delituoso, mas, também, por evitarem que a inocentes sejam imputados crimes que não cometeram.

É nessa linha que o art. 158 do Código de Processo Penal (BRASIL, 1941) veda a possibilidade de que uma eventual confissão do acusado suplante a necessidade da realização do exame de corpo de delito. Tal ferramenta jurídica viabiliza a mobilização segura e eficiente de princípios como o da presunção da inocência, expresso no art. $5^{\circ}$ da Constituição Federal (BRASIL, 1988) e, quando associada ao procedimento pericial pertinente, contribui para que se alcance um equilíbrio adequado entre os direitos individuais e os da sociedade.

Daniel Da Silva Carvalho

Polícia Federal

Licenciado em Física e mestre em CiênCia de Materiais, pela Universidade de Brasília. Atua no Serviço de Perícia Papiloscópica do Instituto Nacional de Identificação. É professor da ACAdemia

Nacional de Polícia e integrante do grupo de pesquisa Papiloscopia Forense da Polícia Federal.

Wiliam Ferreira da Cunha

UNIVERSIDAdE DE BRASílIA - UnB

É Doutor em Física (2009) e professor Associado 2 da Universidade de Brasília - UnB. É pesQuisador do CNPQ e membro do Núcleo de Física Atômica e Molecular do Instituto de Física da UnB, tendo

75 ARTIGOS PUBLICADOS EM REVISTAS CIENTÍFICAS INTERNACIONAIS INDEXADAS E ORIENTADO ESTUDANTES de mestrado e doutorado. Graduado em Física e Engenharia Elétrica e estudante de Direito Na mesma instituição. Atualmente é Diretor no

Ministério da EducaÇão - MEC. 
Bernardo José Munhoz Lobo

Polícia Federal

Qú́mico Industrial. EsPecialista em IDENTIFICAÇÃo Humana, COM AÇốES Voltadas ao desenvolvimento DA PAPILOSCOPIA E SUAS TÉCNICAS PERICIAIS. ATUA no Serviço de Perícia Papiloscópica do Instituto Nacional de IdentificaÇão, como Papiloscopista Policial Federal.

\title{
Pedro Henrique de Oliveira Neto \\ UNIVERSIDADE DE BRASÍLIA - UNB
}

Possui Graduação, Mestrado e Doutorado em Física, pela Universidade de Brasília e Pós-doutorado No Departamento de Química do MassachusetTs

Institute of Technology (MIT). Atualmente é PROFESSOR ASSOCIADO 2 DA UNIVERSIDADE DE BRASÍLIA.

TEM EXPERIÊNCIA NA Área DE Física, COM ÊNFASE EM Física da Matéria Condensada, Estrutura Eletrônica e Dinâmica Molecular, atuando principalmente no ESTUDO DA DINÂMICA DE TRANSFERÊNCIA DE CARGA E ENERGIA EM MATERIAIS ORGÂNICOS E ESTRUTURAS DE BAIXA DIMENSIONALIDADE.

\section{The Revealing Power and The Process Of Adhesion to the Traces Present in Latent FINGERPRINTS}

\begin{abstract}
Through a review of the specialized literature, this study aims at disclosing and detailing the technical-scientific aspects related to some of the factors that influence the process of adhesion of the revealing powder to the traces present in the latent fingerprints. Some of the most commonly used types of powders will also be presented. The distance, purity, and chemical nature of the components of the powder-printed papillary ridge interface will determine whether the disclosure will be effective or not. In this sense, it will be evident that the energy balance between the adhesive and cohesive forces at the powderpapillary ridge printed interface is related to intermolecular interactions, size, shape, free surface energy, and wettability between the components of that interface.
\end{abstract}


KEYwords: Adhesion. Revealing powder. Physical process. Latent fingerprint. Porous surfaces. Human identification. Human rights.

\section{El Polvo Revelador y su Proceso de Adhesión a los Restos Presentes en las IMpresiones PAPIlares Latentes}

\section{RESUMEN}

Mediante una revisión de la literatura especializada, este estudio tiene como objetivo difundir y detallar los aspectos técnico-científicos relacionados con algunos de los factores que influyen en el proceso de adhesión del polvo revelador a los remanentes presentes en las impresiones papilares latentes. También se presentarán algunos de los tipos de polvos más utilizados. La distancia, la pureza y la naturaleza química de los componentes de la interfaz impresa de la cresta papilar determinarán si el revelado será eficaz o no. En este sentido, será evidente que el balance energético entre las fuerzas adhesivas y cohesivas en la interfaz de cresta-polvo papilar impresa está relacionado con interacciones intermoleculares, tamaño, forma, energía de superficie libre y humectabilidad entre los componentes de esa interfaz.

\section{REFERÊNCIAS}

ANUSAVICE, K. J. et al. Phillips' science of dental materials. [S.I.]: Elsevier, 2013.

ASHBAUGH, D. R. Quantitative-Qualitative Friction Ridge Analysis: an introduction to basic and advanced ridgeology. New York: CRC Press LLC, 1999.

ATKINS, P.; PAULA, J. D. Físico-Química, Volume 2. Rio de Janeiro: LTC, 2008.

BANDEY, H. L.; GILSON, A. P. The Powders Process, Study 2: Evaluation of Fingerprint Powders on smooth surfaces. HOSDB 
Fingerprint Development and Imaging Newsletter, v. 08/06, n. Special Edition, February 2006.

BARROS, R. M. Emprego de nanomateriais para análise multiinformacional de impressões digitais latentes. Tese (Doutorado) Universidade de Brasília, Brasilia, 2019.

BRASIL. Código de Processo Penal (1941). Decreto-Lei no 3.689, de 3 de outubro de 1941. Disponível em: http://www.planalto.gov.br/ ccivil_03/decreto-lei/Del3689Compilado.htm. Acesso em: 11 set. 2020.

BRASIL. Constituição Federal (1988). Constituição da República Federativa do Brasil, de 5 de outubro de 1988. Disponível em: http:// www.planalto.gov.br/ccivil_03/constituicao/constituicao.htm.

Acesso em: 11 set. 2020.

BERG, J. C. Wettability - Surfactant Science Series, Volume 49. [S.l.]: CRC Press, 1993.

BERGER, J. L. Widescreen.org, 1995. Disponivel em: https://www. widescreen.org/aspect_ratios.shtml. Acesso em: 14 maio 2020.

BLEAY, S. M. et al. Fingerprint Development Techniques. [S.I.]: Wiley, 2018.

BUMBRAH, G. S.; SODHI, G. S.; KAUR, J. Oil Red O (ORO) reagent for detection of latent fingermark: a review. Egyptian Journal of Forensic Sciences, v. 9, n. 1, p. 3, jan. 2019.

CARVALHO, D. D. S. Determinação do sexo a partir da densidade de cristas papilares e da contagem de albodatilares em brasileiros. Dissertação (Mestrado) - Universidade de Brasília, Brasília, 2019.

CHAMPOD, C. et al. Fingerprint and Other Ridge Skin Impressions. [S.l.]: CRC Press, Taylor \& Francis Group, 2016.

CONTRIBUTORS, W. C. File: comparison of surface area vs volume of shapes.svg. Disponivel em: https://commons.wikimedia.org/wiki/ File:Comparison_of_surface_area_vs_volume_of_shapes.svg. Acesso em: 06 fev. 2020.

DARVELL, B. W. Materials science for dentistry. Birmingham: Elsevier, 2018. 
DAVIES, G. A. et al. Contact angles of liquids on organic solids. Nature Publishing Group, v. 209, n. 2028, p. 1126-1127, 1966. DOI: 10.1038/2091126a0.

DILAG, J. et al. Cadmium sulfide quantum dot/chitosan nanocomposites for latent fingermark detection. Forensic Science International, v. 187, p. 97-102, April 2009.

EUROPEAN NETWORK OF FORENSIC SCIENCE INSTITUTES. Best Practice Manual for Fingerprint Examination. [S.1.]: ENFSI, 2015.

FAULDS, H. Dactylography, or the study of Fingerprints. Milner: Halifax, 1912.

FREITAS, A. F. et al. Papiloscopia Forense. Caderno didático ANP. Brasília: Academia Nacional de Polícia, 2019.

GIROD, A. et al. Composition of fingermark residue: A qualitative and quantitative review. Forensic Science International, v. 223, p. 1024, jun 2012.

GOODWIN, J. W. Colloids and Interfaces with Surfactants and Polymers: an introduction. Portland: John Woley \& Sons Ltd, 2004.

HALLIDAY, D.; RESNICK, R.; WALKER, J. Fundamentos da Física 3 Eletromagnetismo. Rio de Janeiro: LTC, 1996.

HAWTHORNE, M. R. Fingerprints: Analysis and understanding. New York: CRC Press Taylor \& Francis Group, 2009.

HOLDER, E. H. et al. The fingerprint Sourcebook. Washington, DC: U.S. Department of Justice, Office of Justice Programs, National Institute of Justice, 2011.

HOLWILL, M. Nanomechanics in van der Waals Heterostructures. Manchester, UK: Espringer Theses ( Doctoral Thesis) - University of Manchester, 2019.

HUNTER, R. J. Foundations of Colloid Science. New York: Oxford university press, 2001.

ISRAELACHVILI, J. N. Intermolecular and surface forces. San Diego: Academic Press Limited, 1992.

JAMES, J. D. et al. Flake Metal Powders for Revealing Latent 
Fingerprints. Journal of Forensic Sciences, v. 36, n. 5, p. 1368-1375, September 1991.

JAMES, J. D. et al. Production and characterisation of flake metal powders for fingerprint detection. Powder Metallurgy, v. 34, p. 39-44, 1991.

JAMIESON, T. et al. Biological applications of quantum dots. Biomaterials, v. 28, p. 4717-4732, 2007.

KEHRWALD, A. M. Estudo da influência da energia livre superficial na molhabilidade e adesão de revestimentos à base de fluorsilanos. Dissertação (Mestrado em Ciência e Engenharia de Materiais) Universidade Federal de Santa Catarina, Florianópolis, 2009.

KLEMEN, K. Physics of surfaces and interfaces. ljubljana : Jozef Stefan International Postgraduate School, 2005.

LOBO, B.J.M. Revelação de impressões digitais em suportes celulósicos e cédulas de dinheiro: uma revisão. Especialização (Identificação Humana) - Academia Nacional de Polícia, Brasília, 2019.

MARTÍNEZ,L.et al. Aspect-ratio and lateral-resolution enhancement in force microscopy by attaching nanoclusters generated by an ion cluster source at the end of a silicon tip. The Review of scientific instruments, v. 82, DOI: 10.1063/1.3556788, 2011.

NEUMANN, A. W. et al. Applied Surface Thermodynics - surfactant science series, Volume 151. [S.1.]: CRC Press, 2011.

NOBEL. The Nobel Prize in Physics 1910 was awarded to Johannes Diderik van der Waals for his work on the equation of state for gases and liquids. The Nobel Prize, 1910. Disponivel em: https://www. nobelprize.org/prizes/physics/1910/summary/. Acesso em: 24 abr. 2020.

O'BRIEN, W. J. Capillary penetration of liquids between dissimilar solids. Michigan: University of Michigan - Doctoral Thesis, 1967.

PASHLEY, R. M.; KARAMAN, M. E. Applied Colloid and Surface Chemistry. England: John Wiley \& Sons Ltd, 2004.

RAGONE, D. V. Thermodynamics of Materials - Volume II. New York: John Wiley \& Sons, 1995. 
RAMOTOWSKI, R. S. Advances in Fingerprint Technology. [S.I.]: CRC Press, 2012.

RICKERBY, R. S.; MATTHEWS, A. Advanced surface coatings: a hand book of engineering. Glasgow: Blackie, 1991.

RYAN, M. Geometria para leigos. [S.1.]: Alta Books, 2019.

SHAW, D. J. Introdução à química dos colóides e de superfícies. São Paulo: Edgard Blucher 1 Universidade de São Paulo, 1975.

SKOOG et al. Fundamentos de Química Analítica. 8a. ed. [S.1.]: Pioneira Thomson Learning, 2006.

SODHI, G. S.; KAUR, J. Powder method for detecting latent fingerprints: a review. Forensic Science International, v. 120, p. 172$176,2001$.

SOMORJAI, G. A.; LI, Y. Introduction to surface chemistry and catalysis. New Jersey: Wiley, 2010.

SOUZA, M. A. et al. The adsorption of methamphetamine on $\mathrm{Ag}$ nanoparticles dispersed in agarose gel - Detection of methamphetamine in fingerprints by SERS. Vibrational Spectroscopy, v. 98, p. 152-157, 2018.

THOMAS, G. L. The physics of fingerprints and their detection. Journal of Physics E: Scientific Instruments, v. 11, 1978.

VELHO, J. A. A Perícia Criminal como instrumento de promoção dos direitos humanos. Brasília: Revista Brasileira de Ciências Policiais, 2020 .

ZIMON, A. D. Adhesion of Dust and Powder. New York: Consultants Bureau, 1982. 